\title{
A Discussion about Surface Diffusion Mechanism for the Adsorption of Basic Green 4 Dye on to Various Nano Structured Carbon Materials
}

\author{
K. T. Karthikeyan* \\ Department of Chemistry, M.A.M. College of Engineering, Trichy, Tamil Nadu, India. \\ K. Jothivenkatachalam \\ Department of Chemistry, BIT campus, Anna University, Trichy, Tamil Nadu, India \\ S. Karthikeyan \\ Department of Chemistry, Chikkanna Government Arts College, Tirupur, Tamil Nadu, India
}

(Received 22 March 2016; Accepted 1 April 2016; Published 28 May 2016)

\begin{abstract}
The investigation of adsorption behavior of Basic Green 4, a basic dye was carried out using multi-walled carbon nanotubes (MWNTs) and nano porous activated carbon materials prepared from Turmeric Industrial Waste (TWAC) as the adsorbents in the batch mode contact time process with respect to initial dye concentration (20, 40 and $60 \mathrm{mg} / \mathrm{L})$, temperature $(303,318$ and $333 \mathrm{~K})$ and $\mathrm{pH}$. The surface area and pore size volumes for the TWAC and MWNTs were estimated by nitrogen adsorption measurements at $77 \mathrm{~K}$. The morphology of the carbon samples were studied by scanning electron microscopy. A comparison of kinetic models applied to adsorption of Basic Green 4 on both TWAC and MWNTs were evaluated for pseudo first-order, pseudo second-order and Elovich models respectively. Results prove that the pseudo second order kinetic model was found to correlate the experimental data well for both adsorbents. Langmuir and Freundlich adsorption isotherm studies were also measured. The film and pore diffusion kinetics were studied to propose plausible mechanism for the adsorption of Basic Green 4 dye using both multi-walled carbon nano tubes (MWNTs) and nano porous activated carbon materials prepared from Turmeric Industrial Waste (TWAC). [DOI: 10.1380/ejssnt.2016.165]
\end{abstract}

Keywords: Basic Green 4 dye; Film and pore diffusion; Adsorption isotherms; Scanning electron microscopy; Chemisorption; Carbon nanotube; Adsorption kinetics; Turmeric industrial waste activated carbon

\section{INTRODUCTION}

Dyes are one of the very essential raw materials for the textile manufacturers across the World. The basic dye is applied in many industries like dyeing wool, cotton, nylon, silk, and modified acrylics. The presence of such a problematic dye pollutants in textile effluents engenders rigorous environmental issues to the living things.

It is kenned that high potential health risk is caused by adsorption of dyes and their breakdown products (toxic amines) through the gastrointestinal tract, skin, lungs, and withal formation of hemoglobin adducts and imbalance of blood formation. It triggers sundry ecological quandaries to environment due to the presence of even a very low percentage of this dye in aqueous media. In order to eschew this it is very much essential to eliminate even the traces of dye from the industrial effluents. For last few decades scientists fixate on good economic adsorption technique by utilizing activated carbon. Activated carbon is one of the efficacious adsorbent for the adsorption of dyes from industrial effluents due to their sizably voluminous surface area, nano porous character and their surface functional groups.

Many reports were identified by using low price carbon adsorbents ready from obtainable waste materials [1].

The surface adsorption properties of nano porous carbon materials for the elimination of pollutants are well proven [2].

Adsorption of hazardous soluble chemicals from waste water in to surface of a solid adsorbent has provided an incipient dimension to wastewater management [3]. To min-

\footnotetext{
* Corresponding author: keteeke@gmail.com
}

imize the treatment expenses incurred by using activated carbon, the research work was carried out by using waste materials as alternative to commercial activated carbon. Plastics waste [4], rice husks [5, 6], fruit stones [7], peat moss $[8,9]$, delonix regia seed shell [10], ipomoea carnia stem waste [11], ferronia limonia(L) Swingle wood apple shell [12] and jetropha curcas [13] are some of the waste materials which have been endeavored for this study. In our lab, the removal of Acid yellow 17 dye by using Turmeric industrial waste activated carbon (TWAC) [14] was successfully achieved. In this current work, multiwalled carbon nano tubes (MWNTs) and nano sized porous activated carbon material prepared from Turmeric Industrial Waste (TWAC) were used to remove Basic Green 4 (BG 4) from aqueous solution with respect to initial dye concentration, temperatures, and $\mathrm{pH}$ as parameters were investigated and also film and pore diffusion modeling [15-17] were studied for this adsorption process.

\section{MATERIALS AND METHODS}

\section{A. Adsorbent}

Turmeric is one of the sizably voluminous cash crops in South India particularly in Erode and Coimbatore districts. The solid waste created is disposed as waste material from the industries causes' environmental drawback. In view of this, an effort has been made to accumulate these solid wastes and converted into useful nano structured activated carbon adsorbents. The study of Turmeric industrial waste material is used as an adsorbent is expected to be economical, environmentally safe 
and it has practical consequentiality.

In order to prepare adsorbents, the waste stuff was first ground and washed with doubly distilled water and then dried. The dried material thus obtained was treated with hydrogen peroxide $(30 \% \mathrm{~W} / \mathrm{V})$ to oxidize the adhering organic matter for about 24 hrs at ordinary temperature. The resulting material was exhaustively washed with doubly distilled water and then subjected to the temperature of $120^{\circ} \mathrm{C}$ for the moisture removal.

The above material was soaked well with $10 \%$ of $\mathrm{H}_{2} \mathrm{SO}_{4}$ solution for a period of 24 hours. At the end of $24 \mathrm{hrs}$ the excess of $\mathrm{H}_{2} \mathrm{SO}_{4}$ solution were decanted off and air-dried. Then the materials were placed in the muffle furnace to carbonized at $400^{\circ} \mathrm{C}$. After carbonization, the obtained carbons were washed sufficiently with $\mathrm{Na}_{2} \mathrm{CO}_{3}$ to remove cations. Then the carbonized material was cleaned with lots of water to remove excess of acid and dried. To eliminate surface molecules and thermal activation, the turn material was treated at $800^{\circ} \mathrm{C}$ for $60 \mathrm{~min}$ in a furnace under $\mathrm{N}_{2}$ flow $\left(100 \mathrm{~cm}^{3} \cdot \mathrm{min}^{-1}\right)$. The resulting carbons were ground in a mill, washed with pure distilled water, and finally dried at $120^{\circ} \mathrm{C}$. The dried powders were sieved to get desired particle size and kept in tight lid container. The resulting carbon named as Turmeric industrial waste activated carbon (TWAC).

The Jatropha curcas oil was used as a precursor for the preparation of Multi walled carbon nano tubes by using Chemical Vapour Deposition process described in our previous work [18] and the product obtained was stored in a vacuum desiccators until used. The resulting nano structured carbon was named as Multi walled carbon nano tubes (MWNTs).

The $\mathrm{N}_{2}$ adsorption-desorption isotherms of activated carbons were measured at $77 \mathrm{~K}$ employing a gas sorption analyzer (NOVA 1000, Quanta Chrome corporation) in order to determine the surface areas and the total pore volumes. The surface areas were calculated with the help of BET equation.

\section{B. Adsorbate}

The textile dye, Basic Green 4, was purchased from sigma- Aldrich (Germany) and all the chemicals used were procured as research grade chemicals and were utilised without purification. A stock solution of Basic Green 4 was made by dissolving $1 \mathrm{~g}$ of dye in $1000 \mathrm{ml}$ of double distilled water and used for further studies.

\section{Surface area and Pore size distribution Analysis}

The $\mathrm{N}_{2}$ adsorption-desorption isotherms of activated carbons were measured at $77 \mathrm{~K}$ using $\mathrm{N}_{2}$ gas sorption analyzer (Nova 1000, Quanta Chrome Corporation) in order to determine the surface area and total pore volume. The surface area calculated using the BET equation [19]. In addition, the $t$-plot method applied to calculate the micropore volume and external surface area (Mesoporous Surface area). The total pore volume estimated using liquid volume of adsorbate $\left(\mathrm{N}_{2}\right)$ at a relative pressure of 0.99 . The surface areas of the samples were calculated from the nitrogen adsorption isotherms by assuming the area of a nitrogen molecule was $0.162 \mathrm{~nm}^{2}$.

\section{SEM Analysis}

The Scanning electron microscopy (SEM) was used as focused electron beam to scan small areas of solid samples with TESCAN VEGA-3, Scanning Electron Microscope at National College, Trichy.

\section{E. Batch mode adsorption studies}

All reagents used were of AR grade (E Merck). $50 \mathrm{ml}$ of Basic Green 4 dye solution of known concentration $\left(\mathrm{C}_{0}\right)$ and initial pH 6.5 was taken in a $100 \mathrm{ml}$ screw-cap conical flask with a required amount of adsorbent and was stirred at a speed of $200 \mathrm{rpm}$ in a thermostatic shaker bath at $30^{\circ} \mathrm{C}$ for a specified period of time. Then the solution was subjected to filtration through a $0.45 \mu \mathrm{m}$ membrane filter. The concentrations of dye in solutions were determined before and after adsorption using UV-spectrophotometer (Elico make). The amount of dye adsorbed and adsorption efficiency were evaluated.

\section{F. Determination of Basic Green 4}

Basic Green 4 dye was estimated spectrophotometrically (Elico UV-Visible Spectrophotometer). The maximum absorption wavelength $\left(\lambda_{\max }\right)$ for Basic Green 4 is measured to be $680 \mathrm{~nm}$.

The amount of Basic Green 4 adsorbed in $\mathrm{mg} / \mathrm{L}$ at time $t$ was estimated by using the following equation;

$$
q_{t}=\frac{C_{0}-C_{t}}{m_{s}} \times V
$$

where $C_{0}$ and $C_{t}$ are the Basic Green 4 concentration in $\mathrm{mg} / \mathrm{L}$ initially and a given time $t$, respectively, $V$ is the volume of the Basic Green 4 solutions in $\mathrm{ml}$ and $\mathrm{ms}$ is the weight of the adsorbent either TWAC or MWNTs. The percentage of removed Basic Green $4(\mathrm{R} \%)$ in solution was calculated using Eq. (2),

$$
\% \text { Removal }=\frac{C_{0}-C_{t}}{C_{0}} \times 100 .
$$

The initial concentration of Basic Green 4, pH and temperature was investigated by varying any one parameters and keeping the other parameters constant.

\section{G. Adsorption dynamics}

The study of adsorption dynamics describes the solute uptake rate and apparently this rate governs the duration of adsorbate uptake at the solid-solution interface. The kinetics of Basic Green 4 (BG 4) adsorption on the activated carbons was analyzed using pseudo first order [20], pseudo second order [21] kinetic models and Elovich equation [22]. The conformity between experimental data and 
the model foretold values were clearly indicated by the correlation coefficients $\left(\mathrm{R}^{2}\right)$. A relatively high $\mathrm{R}^{2}$ value indicates that the model successfully describes the kinetics of Basic Green 4 (BG 4) adsorption.

\section{H. The pseudo first-order equation}

The pseudo first-order equation [20] is commonly represented as follows.

$$
\frac{d q_{t}}{d t}=k_{1}\left(q_{e}-q_{t}\right)
$$

where $q_{e}$ and $q_{t}$ are the adsorption capacity at equilibrium and at time $t$, respectively $\left(\mathrm{mg} \cdot \mathrm{g}^{-1}\right), k_{1}$ is the rate constant of pseudo first-order adsorption, $1 / \mathrm{min}$.

After integration and applying boundary conditions $t=$ 0 to $t=t$ and $q_{t}=0$ to $q_{t}=q_{t}$, the integration form of Eq. (3) becomes,

$$
\log \left(q_{e}-q_{t}\right)=\log \left(q_{e}\right)-\frac{k_{1}}{2.303} \times t
$$

The value of $\log \left(q_{e}-q_{t}\right)$ were linearly correlated with $t$. The plot of $\log \left(q_{e}-q_{t}\right)$ vs $t$ should show a linear relationship from which $k_{1}$ and $q_{e}$ can be determined from the slope and intercept of the plot, respectively.

\section{The pseudo second-order equation}

The pseudo second-order adsorption kinetic rate equation is expressed as [21]

$$
\frac{d q_{t}}{d t}=k_{2}\left(q_{e}-q_{t}\right)^{2}
$$

where $k_{2}$ is the rate constant of pseudo second order adsorption $\left(\mathrm{g} \cdot \mathrm{mg}^{-1} \cdot \mathrm{min}^{-1}\right)$. For the boundary conditions $t=0$ to $t=t$ and $q_{t}=0$ to $q_{t}=q_{t}$, the integrated form of Eq. (5) becomes

$$
\frac{1}{q_{e}-q_{t}}=\frac{1}{q}+k_{2} t
$$

which is the integrated rate law for pseudo second-order reaction. Equation (6) can be rearranged to acquire Eq. (7), which has a linear form

$$
\frac{t}{q_{t}}=\frac{1}{k_{2} q_{e}^{2}}+\frac{1}{q_{e}}(t)
$$

If the initial adsorption rate $h\left(\mathrm{mg} \cdot \mathrm{g}^{-1} \cdot \mathrm{min}^{-1}\right)$ is

$$
h=k_{2} q_{e}^{2}
$$

then Eqs. (7) and (8) become

$$
\frac{t}{q_{t}}=\frac{1}{h}+\frac{1}{q_{e}}(t)
$$

The plot of $\left(t / q_{t}\right)$ vs $t$ of Eq. (9) should give a linear relationship from with a slope of $1 / q_{e}$ and an intercept of $1 / k_{2} q_{e}^{2}$ of the plot, respectively.

\section{J. The Elovich equation}

The Elovich model equation is generally expressed [22] as

$$
\frac{d q_{t}}{d t}=\alpha \exp \left(-\beta q_{t}\right)
$$

where $\alpha$ is the initial adsorption rate $\left(\mathrm{mg} \cdot \mathrm{g}^{-1} \cdot \mathrm{min}^{-1}\right)$, and $\beta$ is the adsorption constant $\left(\mathrm{g} \cdot \mathrm{mg}^{-1}\right)$. To elucidate the Elovich equation, assumed $\alpha \beta_{t}>>1$ and by applying the boundary conditions $q_{t}=0$ at $t=0$ and $q_{t}=q_{t}$ at $t=t$, the Eq. (10) becomes

$$
q_{t}=\ln (\alpha, \beta) \frac{1}{\beta}+\frac{1}{\beta} \ln t .
$$

If Basic Green 4 (BG 4) adsorption fits the Elovich model a plot of $q_{t}$ vs $\ln t$ should turnout a linear relationship with slope of $(1 / \beta)$ and an intercept of $(1 / \beta) \ln (\beta)$.

\section{K. Isotherm models}

The study of the Langmuir isotherm is essential in assessing the adsorption efficiency of the adsorbent. This exercise is also helpful in optimizing conditions for efficient adsorption. In this respect, the Langmuir isotherm is important, though the conditions and the drawbacks of this model have been well recognized [23]. The Langmuir and the rearranged Langmuir equations are given below.

$$
\begin{gathered}
q_{e}=\frac{1}{Q_{0} \cdot b} \cdot \frac{1}{C_{e}}+\frac{1}{Q_{0}}, \\
\frac{C_{e}}{q_{e}}=\frac{C_{e}}{Q_{0}}+\frac{1}{Q_{0} \cdot b},
\end{gathered}
$$

where $q$ is the amount of dye removed at equilibrium $(\mathrm{mg} / \mathrm{g}), C_{e}$ is the equilibrium concentration of dye $(\mathrm{mg} / \mathrm{L}), Q_{0}$ is the Langmuir constant, related to the adsorption capacity $(\mathrm{mg} / \mathrm{g}), b$ is the Langmuir constant, related to the energy of adsorption $(\mathrm{L} / \mathrm{mg})$.

\section{Freundlich Isotherm}

At equilibrium conditions, the adsorbed amount, $q_{e}$ can also be predicted by using the Freundlich equation [24].

$$
q_{e}=k_{f} C_{e}^{1 / n},
$$

where $\mathrm{q}_{e}$ is dye concentration in solid at equilibrium $(\mathrm{mg} / \mathrm{g}), \mathrm{C}_{e}$ is dye concentration in solution at equilibrium $(\mathrm{mg} / \mathrm{L}), \mathrm{k}_{f}$ is measure of adsorption capacity, and $n$ is adsorption intensity. A logarithmic form of the above equation is

$$
\log q_{e}=\log k_{f}+\frac{1}{n} \log C_{e} .
$$

The values of $n$ and $k_{f}$ were determined from the plot $\log C_{e}$ vs $\log q_{e}$. Here, $k_{f}$ is the indication of the adsorbent capacity and $1 / n$ is a measure of surface heterogeneity, ranging between 0 and 1 , enhancing more heterogeneous as its value gets nearer to zero. 
TABLE I. Characteristics for the both TWAC and MWNTs carbon materials.

\begin{tabular}{lcc}
\hline \hline Parameter & TWAC & MWNTs \\
\hline Bulk density $(\mathrm{g} / \mathrm{ml})$ & 0.45 & 0.47 \\
Ash content (\%) & 2.05 & 2.17 \\
$\mathrm{pH}$ & 6.9 & 6.5 \\
Moisture content (\%) & 3.17 & 2.74 \\
Surface area $\left(\mathrm{m}^{2} / \mathrm{g}\right)$ & 603 & 621 \\
Solubility in water $(\%)$ & 0.8 & 0.62 \\
Solubility in 0.25 M HCl $(\%)$ & 1.15 & 0.92 \\
Decolorizing power (mg/g) & 40.3 & 44.8 \\
Iodine number (mg/g) & 512 & 457 \\
pH ${ }_{\text {zpc }}$ & 5.9 & 6.4 \\
Carbonyl (mmol/g) & 0 & 0 \\
Lactonic $(\mathrm{mmol} / \mathrm{g})$ & 0.038 & 0.34 \\
Phenolic $(\mathrm{mmol} / \mathrm{g})$ & 0.013 & 0.11 \\
Acidic $(\mathrm{mmol} / \mathrm{g})$ & 0.019 & 0.016 \\
Basic $(\mathrm{mmol} / \mathrm{g})$ & 0.412 & 0.397 \\
\hline \hline
\end{tabular}

\section{RESULTS AND DISCUSSION}

\section{A. Characterization of adsorbent}

Physico-chemical characterization of the adsorbents was presented in Table I.

\section{B. Optimum pH}

The adsorption behavior of Basic Green 4 on the chosen adsorbents were studied over a wide $\mathrm{pH}$ range of 2.0-10.0. Figure 1 pellucidly shows that the higher $\mathrm{pH}$ favors the extent of adsorption of Basic Green 4 over the chosen adsorbent and a very poor adsorption was observed at lower $\mathrm{pH}$ condition. From the figure, it is proved that maximum uptake of the Basic Green 4 (BG 4) is observed only from pH 6.5 and thereafter on both TWAC and MWNTs. This may be due to the effect of pKa of $\mathrm{BG} 4$ dye and $\mathrm{pH}_{\mathrm{zpc}}$ of chosen adsorbents. In general the basic dye adsorption may be very poor at low $\mathrm{pH}$ values in accordance with a presupposed ion-exchange mechanism of the adsorption. The $\mathrm{pH}_{\mathrm{zpc}}$ are found to be at $\mathrm{pH} 5.9$ and 6.4 for the chosen TWAC adsorbent and MWNTs respectively. This is a convenient index of a surface that adsorbents becomes either positively charged or negatively charged as a function of $\mathrm{pH}$. When the $\mathrm{pH}$ of the solution is lower the $\mathrm{pH}_{\mathrm{zpc}}$, the surface area of the adsorbents will become positively charged. Meanwhile, the surface of the adsorbents will become negatively charged when the solution $\mathrm{pH}$ is greater than $\mathrm{pH}_{\mathrm{zpc}}[25]$.

The removal of basic dye BG 4 is increased from $\mathrm{pH}$ 6.50 above is mainly because the surface charge of the chosen adsorbents are negative after the $\mathrm{pH} 5.90\left(\mathrm{pH}_{\mathrm{zpc}}\right.$ for TWAC), and $\mathrm{pH} 6.40\left(\mathrm{pH}_{\mathrm{zpc}}\right.$ for MWNTs) respectively,

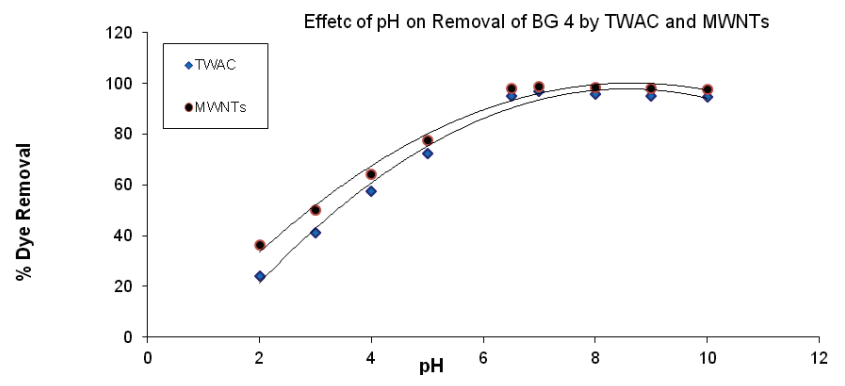

FIG. 1. Effect of $\mathrm{pH}$ on the percentage of removal of Basic Green 4(BG 4) by TWAC and MWNTs.

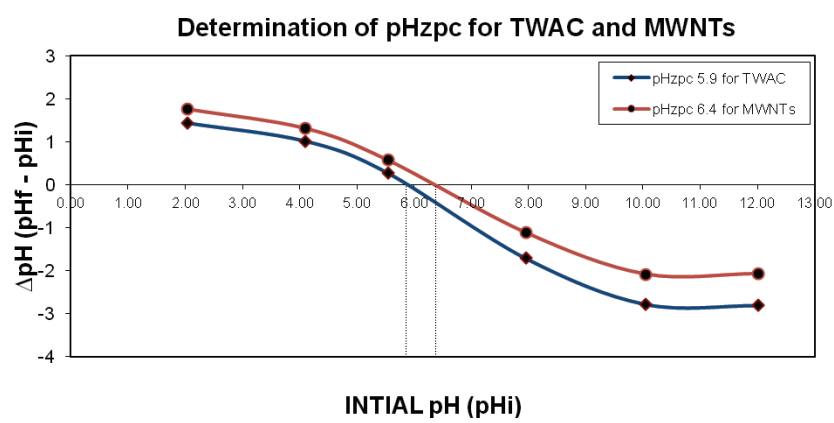

FIG. 2. Determination of $\mathrm{pH}_{\mathrm{zpc}}$ for TWAC and MWNTs.

thus high electrostatic attraction between the negatively charged surface of the adsorbents and the cations of BG 4 and also the dye BG 4 having the pKa of 6.90. Till the solution $\mathrm{pH}$ 6.50, the removal of basic dye BG 4 was very poor due to the higher coulombic repulsions between the positively charged surface of both TWAC and MWNTs and the cations of BG 4 in the adsorption processes.

For this reason, the $\mathrm{pH} 6.5$ was selected as optimum $\mathrm{pH}$ for the effective removal of Basic Green 4 dye (BG 4) and used the same for further studies.

\section{Determination of zero point charge $\left(\mathrm{pH}_{\mathrm{zpc}}\right)$}

The $\mathrm{pH}$ of the zero point charge $\left(\mathrm{pH}_{\mathrm{zpc}}\right)$ has been determined by adding $0.2 \mathrm{~g}$ of adsorbent in glass stopper bottle containing $20 \mathrm{ml}$ of $0.01 \mathrm{M} \mathrm{NaCl}$ solutions. The initial $\mathrm{pH}$ of these solutions has been altered by the addition of either $0.1 \mathrm{M} \mathrm{NaOH}$ or $0.1 \mathrm{M} \mathrm{HCl}$. The bottles have been placed in an incubator shaker at $298 \mathrm{~K}$ for 24 $\mathrm{h}$, and the final $\mathrm{pH}$ of supernatant has been measured. The $\Delta \mathrm{pH}=\mathrm{pH}$ (final) $-\mathrm{pH}$ (initial) have been plotted between the initial $\mathrm{pH}$ and the $\mathrm{pH}$ at which $\Delta \mathrm{pH}$ was zero was taken as the $\mathrm{pH}_{\mathrm{zpc}}$ for the corresponding adsorbent. Figure 2 clearly shows that the $\mathrm{pH}_{\mathrm{zpc}}$ values were 5.90 and 6.40 for TWAC and MWNTs, respectively.

\section{Scanning Electron Microscope}

SEM micrographs (Fig. 3(a) and 3(b)) of TWAC and MWNTs showed cavities, pores and more rough surfaces 
TABLE II. The adsorption kinetic model rate constants for TWAC and MWNTs at various temperatures

\begin{tabular}{|c|c|c|c|c|c|c|c|c|c|}
\hline \multirow[b]{2}{*}{ Adsorbent } & \multirow[b]{2}{*}{ Initial Temperature } & \multicolumn{2}{|c|}{ Pseudo first order } & \multicolumn{3}{|c|}{ Pseudo Second order } & \multicolumn{3}{|c|}{ Elovich Model } \\
\hline & & $\begin{array}{c}\mathrm{k}_{1} \\
\min ^{-1}\end{array}$ & $r^{2}$ & $\begin{array}{c}\mathrm{k}_{2} \\
\mathrm{~g} \mathrm{mg}^{-1} \\
\min ^{-1}\end{array}$ & $\begin{array}{c}\mathrm{h} \\
\mathrm{mg} \mathrm{g}^{-1} \\
\min ^{-1}\end{array}$ & $\mathrm{r}^{2}$ & $\begin{array}{c}\beta \\
\mathrm{g} \min ^{-1}\end{array}$ & $\begin{array}{c}\alpha \\
\operatorname{mg~g}^{-1} \\
\min ^{-1}\end{array}$ & $r^{2}$ \\
\hline \multirow{3}{*}{ TWAC } & $30^{\circ} \mathrm{C}$ & 0.0334 & 0.9854 & 0.00112 & 0.9309 & 0.9938 & 0.2452 & 2.9473 & 0.9532 \\
\hline & $45^{\circ} \mathrm{C}$ & 0.0343 & 0.9797 & 0.0011 & 0.7876 & 0.9957 & 0.251 & 3.7342 & 0.9588 \\
\hline & $60^{\circ} \mathrm{C}$ & 0.0354 & 0.984 & 0.00109 & 0.6526 & 0.997 & 0.2608 & 5.0142 & 0.9619 \\
\hline \multirow{3}{*}{ MWNTs } & $30^{\circ} \mathrm{C}$ & 0.0299 & 0.9744 & 0.00111 & 0.9071 & 0.9954 & 0.2435 & 2.9909 & 0.9797 \\
\hline & $45^{\circ} \mathrm{C}$ & 0.0304 & 0.982 & 0.00108 & 0.7776 & 0.9966 & 0.2507 & 3.8739 & 0.9765 \\
\hline & $60^{\circ} \mathrm{C}$ & 0.0318 & 0.992 & 0.00106 & 0.6609 & 0.9973 & 0.2544 & 4.8423 & 0.9708 \\
\hline
\end{tabular}

(a)

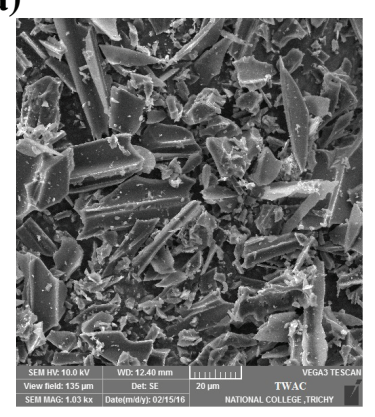

(b)

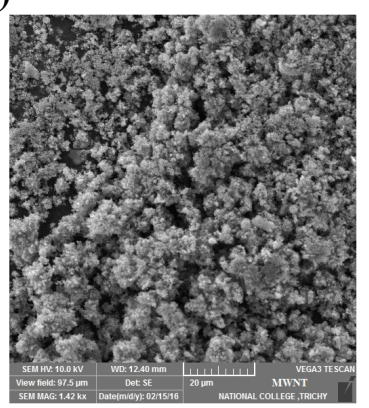

FIG. 3. SEM Image of (a) TWAC and (b) MWNTs.

on the carbon samples. Granular pores and cavities will increase the surface area of the adsorbent. SEM photograph of TWAC and MWNTs shows that the surface is pitted and fragmented and the surface area will be enhanced by the presence of more porosity and cave type openings, which can hold more solute from solution during adsorption [26].

\section{E. Effect of concentration}

The batch mode adsorption studies were determined by using three different concentrations of Basic Green 4 viz. $20 \mathrm{mg} / \mathrm{L}, 40 \mathrm{mg} / \mathrm{L}$ and $60 \mathrm{mg} / \mathrm{L}$ at $\mathrm{pH} 6.5$, and at the reaction temperature of $30^{\circ} \mathrm{C}$ were selected for the adsorption study. Figure 4(a) and 4(b), clearly reveals that the extent of adsorption of Basic Green 4 on the adsorbents TWAC and MWNTs decreases as initial dye concentration increases.

\section{F. Effect of Temperature on kinetic rate constant and rate parameters}

Here the adsorption studies were followed with fixed initial dye concentration $(20 \mathrm{mg} / \mathrm{L})$, at $\mathrm{pH} 6.5$ and at different temperature viz. $30^{\circ} \mathrm{C}, 45^{\circ} \mathrm{C}$ and $60^{\circ} \mathrm{C}$. The analysis of the data in (Table II) reveals that the influence of temperature of the BG 4 on both adsorbents have very

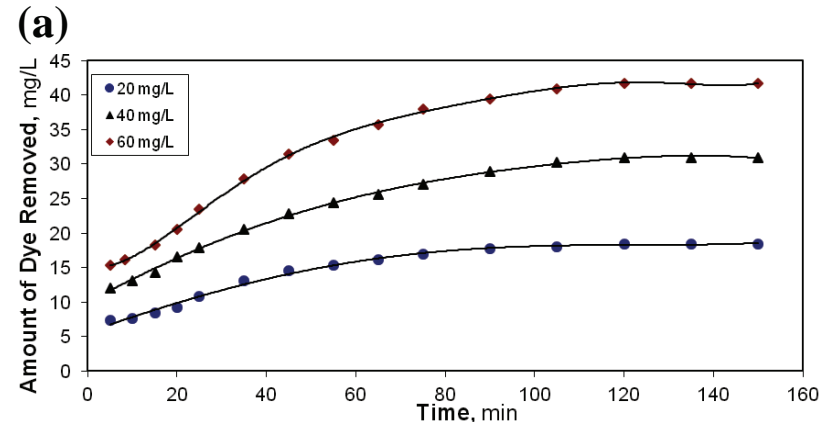

(b)

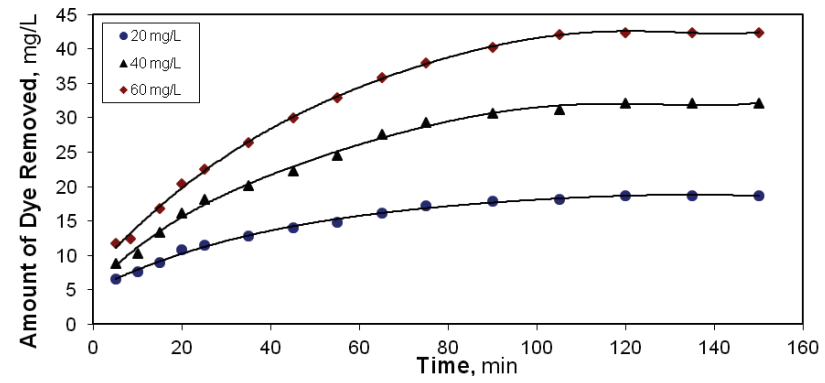

FIG. 4. Effect of concentration on adsorption of Basic Green 4(BG 4) (a) over TWAC and (b) over MWNTs.

little influence on the pseudo first order rate constants. But the influence on Elovich and pseudo second order rate constant is neither appreciable nor little.

It is obvious that the adsorption of BG 4 on the adsorbents TWAC and MWNTs are best described by second order rate equation with higher regression coefficient value.

\section{G. Thermodynamic Parameter}

The thermodynamic parameters obtained for the adsorption studies were estimated with the help of the below 
TABLE III. Thermodynamic parameters on the adsorption of BG 4 on TWAC and MWNTs.

\begin{tabular}{|c|c|c|c|c|c|}
\hline \multirow{2}{*}{ Adsorbent } & \multicolumn{3}{|c|}{$\Delta \mathrm{G} \times 10^{4}\left(\mathrm{~kJ} \mathrm{~mol}^{-1}\right)$} & \multirow{2}{*}{$\begin{array}{c}\Delta \mathrm{H} \\
\left(\mathrm{kJ} \mathrm{mol}^{-1}\right)\end{array}$} & \multirow{2}{*}{$\begin{array}{c}\Delta \mathrm{S} \\
\left(\mathrm{kJ} \mathrm{mol}{ }^{-1}\right)\end{array}$} \\
\hline & $30^{\circ} \mathrm{C}$ & $45^{\circ} \mathrm{C}$ & $60^{\circ} \mathrm{C}$ & & \\
\hline TWAC & -12756 & -18469 & -29165 & 20.43 & 80.76 \\
\hline MWNTs & -13847 & -11907 & -16023 & 1.24 & 17.67 \\
\hline
\end{tabular}

mentioned equation [27].

$$
\begin{aligned}
K_{c} & =\frac{C_{A e}}{C_{e}}, \\
\Delta G & =-R T \ln K_{c}, \\
\log K_{c} & =\frac{\Delta S}{2.303 R}-\frac{\Delta H}{2.303 R T} .
\end{aligned}
$$

$K_{c}$ is equilibrium constant, $C_{A e}$ is the solid phase concentration at equilibrium, $C_{e}$ is residual concentration at equilibrium, $R$ is gas constant $(\mathrm{J} / \mathrm{mole})$ and $T$ is the temperature in Kelvin.

$\Delta H$ and $\Delta S$ were obtained from the slope and intercept of Van't Hoff plot $\left(1 / t\right.$ vs $\left.\ln K_{c}\right)$. Table III gives the value of $\Delta G, \Delta S$ and $\Delta H$ for the adsorption of TWAC and MWNTs. The negative values of free energy change $(\Delta G)$ shows that the feasibility and spontaneous nature of adsorption of TWAC as well as MWNTs. The positive value of $\Delta S$ is due to the increased randomness during the time of adsorption. The positive value of $\Delta H$ also indicates the reaction is endothermic.

\section{H. Determination of Freundlich and Langmuir isotherms}

Freundlich and Langmuir isotherm constants were determined from the plots of $\log q_{e}$ vs $\log C_{e}$ and $C_{e} / q_{e}$ vs $C_{e}$ for BG 4 at $303,318,333 \mathrm{~K}$ respectively. The data fairly fitwith isotherms and propose plausible mechanism of adsorption involved in this process.

The isotherm constants and the correlation coefficient, $\mathrm{r}^{2}$ with the experimental data is given in Table IV. As seen from Table IV, the parameter correlation coefficient $\left(\mathrm{r}^{2}\right)$ related to the adsorption increase with an increase in temperature. This was consistent with the experimental observation; it also indicates that $n$ (intensity of adsorption) is higher than unity, showing that the BG 4 is favourably adsorbed by both TWAC and MWNTs at all temperatures studied.

\section{Mechanism}

Because of the significant correlation coefficients obtained using pseudo-first order and pseudo second order models, it was difficult to conclude which adsorption mechanism actually occurred. In an attempt to identify the specific adsorption mechanism, other sources of information are reviewed. The morphology, defects and active sites of carbon nanotubes played an important role
TABLE IV. Isotherm rate constants and parameters on BG 4 over TWAC and MWNTs

\begin{tabular}{cccccccc}
\hline \hline \multirow{2}{*}{ Adsorbent } & \multirow{2}{*}{\begin{tabular}{c} 
Temp. \\
\cline { 3 - 8 }
\end{tabular}} & \multicolumn{3}{c}{ Langmuir } & \multicolumn{3}{c}{ Freundlich } \\
\cline { 3 - 8 } TWAC & $45^{\circ} \mathrm{C}$ & 6.9856 & 130.63 & 0.9199 & 2.2103 & 15.237 & 0.9895 \\
& $30^{\circ} \mathrm{C}$ & 5.0637 & 123.08 & 0.9185 & 2.0982 & 11.896 & 0.9825 \\
& $60^{\circ} \mathrm{C}$ & 10.5346 & 135.05 & 0.92 & 2.3047 & 19.372 & 0.9861 \\
& $30^{\circ} \mathrm{C}$ & 5.4969 & 54.23 & 0.9928 & 2.4618 & 8.6872 & 0.8523 \\
MWNTs & $45^{\circ} \mathrm{C}$ & 4.5037 & 64.72 & 0.9929 & 2.5374 & 9.9462 & 0.9426 \\
& $60^{\circ} \mathrm{C}$ & 5.7873 & 74.66 & 0.9986 & 2.224 & 9.7832 & 0.9085 \\
\hline
\end{tabular}

in the adsorption of the dyes onto surface of carbon nanotubes. If it consists of multiple concentric tubes then it is called Multi-Walled Carbon Nanotubes (MWNTs) [28]. The outer layer of MWNTs consist of graphitic sheets or graphene, which exhibiting a special sidewall curvature and possessing a $\pi$-conjugative structure with a highly hydrophobic surface. These unique properties and the hexagonal arrays of carbon atoms in graphite sheets of MWNTs surface have strong interactions which allow them to interact with other molecules or atoms through $\pi-\pi$ electronic and hydrophobic interactions which make MWNTs a promising adsorbent material $[29,30]$.

The adsorption on MWNTs is relatively higher as compared to such widely used materials as activated carbons due to the unique properties exhibited by MWNTs [31]. The possible adsorption sites for binding of dye molecule on MWNTs and activated carbon are shown as schematic diagram in Figure 5 [32].

1) Internal sites-these sites are found within the hollow structure of tubes and available only when ends of the tube are open;

2) Interstitial channels - these sites are easily accessible for the adsorbate species and found in the interior space of the bundle;

3) External grooves - the grooves present on the periphery of a nanotube where two adjacent parallel tubes meet.

4) Exposed surface site or outside surface - outside surface site are highly accessible for the adsorbate and found on the curved surface of individual nanotubes.

The radius of gyration of organic vapors and common organic molecules are too large to be adsorbed between the interlayer spacing of MWNTs which is $0.34 \mathrm{~nm}$. Therefore, adsorption can occur on the external wall surface or through capillary condensation in the MWNTs pores [33]. The inner sites would also be inaccessible for adsorbate molecules because these cavities would be blocked. Generally, the surface with various defects is able to exhibit relatively high surface reactivity toward the adsorption and activation of adsorbate. In addition, from experimental point of view, it is quite difficult to accurately study the adsorption process at defect sites of solid surface [34]. The nature of adsorbate also played a crucial role in the adsorption onto CNTs. 


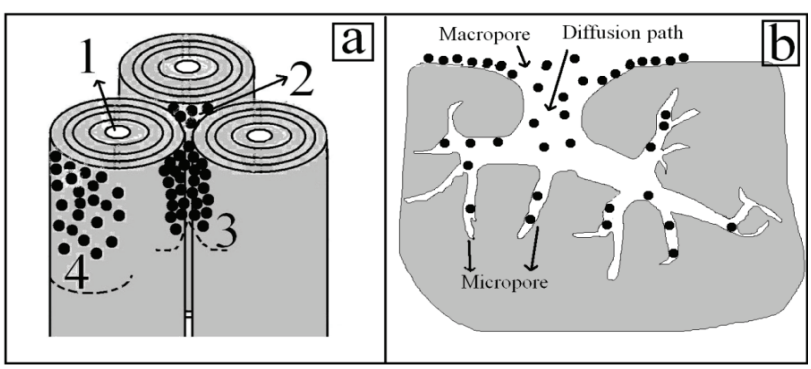

FIG. 5. Possible adsorption sites for binding of dyes on (a) MWNTs and (b) TWAC. 1) Internal sites - these sites are found within the hollow structure of tubes and available only when ends of the tube are open; 2) Interstitial channels - these sites are easily accessible for the adsorbate species and found in the interior space of the bundle; 3) External grooves - the grooves present on the periphery of a nanotube where two adjacent parallel tubes meet and 4) Exposed surface site or outside surface - outside surface site are highly accessible for the adsorbate and found on the curved surface of individual nanotubes.

In this adsorption mechanism, the dye species migrate towards the surface of the adsorbent. This sort of migration continues till the concentration of the adsorbate species, adsorbed, on to the surface of the adsorbent. Once equilibrium is acquired, the migration of the solute species from the solution stops. Under this situation, it is possible to measure the magnitude of the distribution of the solute species between the liquid and solid phases. The amount of this kind of distribution is a degree of the efficiency of the chosen adsorbent in the adsorbate groups.

When a ground solid adsorbent material is made in contact with a solution containing dye species, the dye species first migrate from the bulk solution to the surface of the liquid film. This surface exerts a diffusion barrier. This barrier may be very important or less important. The involvement of a significant quantum of diffusion barrier shows the important role taken up by the film diffusion in the adsorption process. Furthermore, the rate of an adsorption process is governed either by external diffusion, internal diffusion or by both types of diffusions.

The external diffusion regulates the movement of the solute species from the solution to the boundary layer of the liquid phase. However, the internal diffusion governs the movement of the solute species from the external surface of the adsorbent to the internal surface of the pores of the adsorbent material [35].

It is now well established, that during the adsorption of dye species over a porous adsorbent, the following three consecutive steps are taken place [36].

(i) transport of the ingoing adsorbate species to external surface of the adsorbent (film diffusion).

(ii) transport of the adsorbate species within the pores of the adsorbent except for a low adsorption, which occurs on the external surface (particle diffusion).

(iii) adsorption of the ingoing adsorbate species on the interior surface of the adsorbent.

Out of these three processes, the third process is considered to be very fast and is not the rate limiting step in the uptake of organic compounds [37]. The remaining two steps shows the below mentioned three possibilities:

Case 1: External transport < internal transport, where rate is controlled by particle diffusion.

Case 2: External transport > internal transport, where the rate is governed by film diffusion.

Case 3: External transport $\approx$ internal transport, which accounts for the transport of the adsorbate species to the boundary and may not be possiblewithin a significant rate, which later on gives rise to the formation of a liquid film enclosed by the adsorbent species with a proper concentration gradient.

In the batch-mode contact time adsorption studies, very quick agitation is maintained. This Basic Green 4 (BG 4) to the transport of the adsorbed species from the solution to the pores of the adsorbent material and this step may control the rate of the adsorption process.

According to Michelson [38] for film diffusion to be ratedetermining step, the value of the film diffusion coefficient, $D_{f}$, should be in the range $10^{-6}-10^{-8} \mathrm{~cm}^{2} / \mathrm{sec}$. If pore diffusion were to the rate limiting, the pore diffusion coefficient, $D_{p}$, should be in the range $10^{-11}$ $10^{-13} \mathrm{~cm}^{2} / \mathrm{sec}$. In order to find out the nature of the process responsible for adsorption on to chosen adsorbents, attempts were made to calculate the diffusion coefficient of the process.

Assuming spherical geometry of the sorbents [39], the overall rate constant of the process can be correlated to the pore diffusion coefficient in conformation with the expression,

$$
t_{1 / 2}=0.03 \frac{r_{0}^{3}}{D_{p}}
$$

or to the film diffusion coefficient in accordance with

$$
t_{1 / 2}=0.23 \frac{r_{0} \cdot d}{D_{f}} \times \frac{\bar{C}}{C}
$$

where $r_{0}$ is radius of the sorbent $(\mathrm{cm}), D_{p}$ and $D_{f}$ are pore diffusion coefficient $\left(\mathrm{cm}^{2} / \mathrm{sec}\right)$ and film diffusion coefficient $\left(\mathrm{cm}^{2} / \mathrm{sec}\right)$ respectively, $\bar{C} / C$ is equilibrium loading of the adsorbent, $d$ is the film thickness $(\mathrm{cm})$ and $t_{1 / 2}$ is the time for half change (sec) .

Since the carbon particles utilized were of the nano porous size range, the average diameter of the particle was taken as $0.0215 \times 10^{-4} \mathrm{~cm}$. Applying these values, the film diffusion coefficients and pore diffusion coefficients were estimated. Then utilizing the pseudo first order rate constant $k_{L}$, for the adsorption of Basic Green 4. The values of $D_{p}$ and $D_{f}$ were estimated as per the given set of operating conditions, and are presented in the Table V.

The present study indicates the $D_{p}$ values in the order of $10^{-13} \mathrm{~cm} / \mathrm{sec}$ and the $D_{f}$ values in the order of $10^{-11}$ for the respective Lagergren plots for Basic Green 4 (BG 4) and hence the investigator concludes that the mechanism of the removal of Basic Green 4 (BG 4) in the present study by adsorbent was complies. 
TABLE V. $\mathrm{D}_{p}$ and $\mathrm{D}_{f}$ values for the chosen adsorbentadsorbate system

\begin{tabular}{ccccc}
\hline \hline Absorbent & $\begin{array}{c}\text { Temperature } \\
{ }^{\circ} \mathrm{C}\end{array}$ & $\mathrm{t}_{1 / 2, S}$ & $\begin{array}{c}\mathrm{D}_{p} \\
10^{-13} \mathrm{~cm}^{2}\end{array}$ & $\begin{array}{c}\mathrm{D}_{f} \\
10^{-11} \mathrm{~cm}^{2}\end{array}$ \\
\hline \multirow{3}{*}{ TWAC } & $30^{\circ} \mathrm{C}$ & 37225.85 & 0.0931 & 0.0613 \\
& $45^{\circ} \mathrm{C}$ & 37792.46 & 0.0917 & 0.0619 \\
& $60^{\circ} \mathrm{C}$ & 38084.18 & 0.091 & 0.0627 \\
& $30^{\circ} \mathrm{C}$ & 37626.26 & 0.0921 & 0.0614 \\
& $45^{\circ} \mathrm{C}$ & 38589.6 & 0.0898 & 0.0616 \\
& $60^{\circ} \mathrm{C}$ & 38589.6 & 0.088 & 0.0628 \\
\hline \hline
\end{tabular}

\section{J. Intra-particle diffusion}

In order to identify the mechanism the general technique involved in the sorption process is by fitting the experimental data in an intra-particle diffusion plot. In earlier studies, researchers showed that the plot of qt versus $t^{0.5}$ represents multi linearity, which indicates the two or more steps involved in the sorption process. According to Weber and Morris, an intra-particle diffusion coefficient $K_{p}$ is defined by the equation:

$$
K_{p}=\frac{q_{t}}{t^{0.5}}+C
$$

Thus the $K_{p}\left(\mathrm{mg} / \mathrm{g} \cdot \mathrm{min}^{0.5}\right)$ value can be attained from the slope of the plot of $q_{t}(\mathrm{mg} / \mathrm{g})$ versus $t^{0.5}$ for Basic Green 4 dye. From Fig. 6(a) and 6(b), it was recognized that the sorption process leads to be proceeded by two phases. The two phases in the intra-particle diffusion plot propose that the sorption process proceeds by surface sorption and intra-particle diffusion. The initial curved portion of the plot shows a boundary layer effect while the second linear portion is due to intra-particle or pore diffusion. The slope of the second linear portion of the plot has been defined as the intra-particle diffusion parameter $K_{p}\left(\mathrm{mg} / \mathrm{g} \cdot \mathrm{min}^{0.5}\right)$. On the other hand, the intercept of the plot reflects the boundary layer effect. The larger the intercept, the greater the contribution of the surface sorption in the rate limiting step. The calculated intra-particle diffusion coefficient $K_{p}$ values for initial dye concentration of 20,40 and $60 \mathrm{mg} / \mathrm{L}$ at $30^{\circ} \mathrm{C}$ for both adsorbents were given in the Table VI.

Since the external Mass transfer and intraparticle diffusion constants varied with initial Basic Green 4 (BG 4) concentration indicating the occurrence of both film diffusion and intra particle diffusion, the sorption data were further analyzed by the kinetic expression given by Boyd [40] as

$$
\begin{aligned}
& F=1-\sum_{N-1}^{\alpha} \frac{1}{n^{2}} \exp \left[-\frac{D_{i} t \pi^{2} n^{2}}{r^{2}}\right], \\
& F=1-\sum_{N-1}^{\alpha} \frac{1}{n^{2}} \exp \left[-n^{2} \beta_{t}\right],
\end{aligned}
$$

where $F$ is the fractional attainment of equilibrium at time $t$ and is obtained by using following equation and $n$
TABLE VI. Intra-particle diffusion coefficient $\left(\mathrm{K}_{p}\right)$ values for the chosen adsorbents-adsorbate system.

\begin{tabular}{cccc}
\hline \hline Adsorbent & $\begin{array}{c}\text { Initial dye } \\
\text { concentration }\end{array}$ & $\begin{array}{c}\text { Intra-particle } \\
\text { diffusion parameter } \\
\mathrm{K}_{p}\left(\mathrm{mg} / \mathrm{g} \mathrm{min}^{0.5}\right)\end{array}$ & Intercept \\
\hline \multirow{7}{*}{ TWAC } & $20 \mathrm{mg} / \mathrm{L}$ & 1.2938 & 4.5581 \\
& $40 \mathrm{mg} / \mathrm{L}$ & 2.1376 & 7.4054 \\
MWNTs & $60 \mathrm{mg} / \mathrm{L}$ & 3.0372 & 8.8268 \\
& $20 \mathrm{mg} / \mathrm{L}$ & 1.2958 & 4.674 \\
& $40 \mathrm{mg} / \mathrm{L}$ & 2.5449 & 4.5906 \\
\hline \hline
\end{tabular}
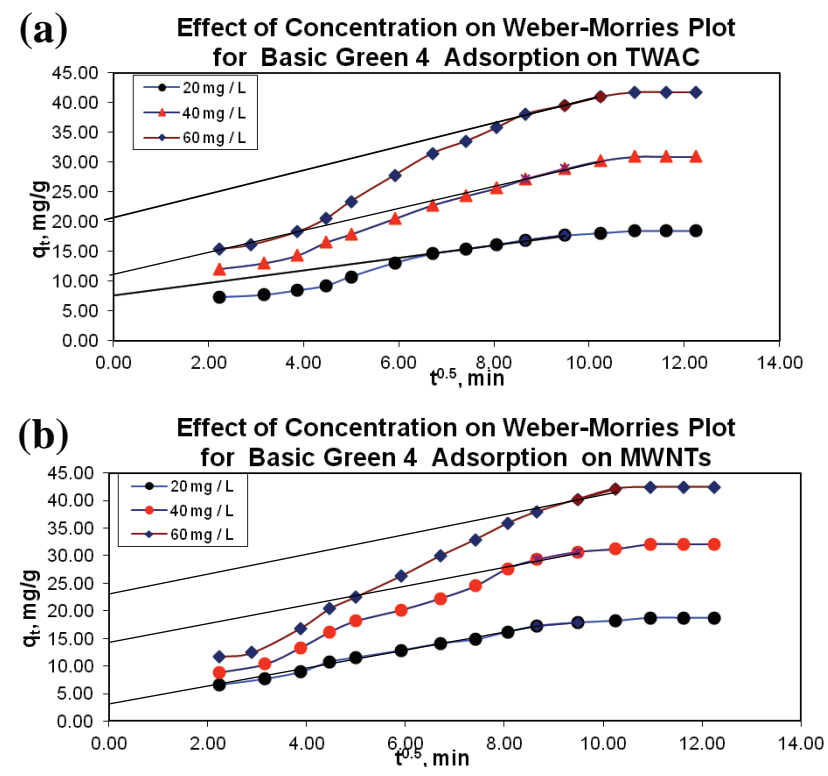

FIG. 6. Effect of concentration on Weber-Morries plot for Basic Green 4 (BG 4) on (a) TWAC and (b) MWNTs.

is the integer value.

$$
F=\frac{q_{t}}{q_{e}}
$$

where $q_{t}$ and $q_{e}$ are the amounts adsorbed at time $t$ and at equilibrium respectively.

On the basis of $F$ values, corresponding values of $B_{t}$ were obtained from Eq. (23) [41].

The $B_{t}$ vs time plots for the sorption of Basic Green 4 (BG 4) over TWAC and MWNTs (Fig. 7(a) and 7(b)) was found to be linear in beginning. Thus the process is seems to be particle diffusion controlled in this region, while during the later deviation from linearity occurs and they also did not pass through the origin throughout concentration range at $30^{\circ} \mathrm{C}, 45^{\circ} \mathrm{C}$ and $60^{\circ} \mathrm{C}$. Thus the overall process can be interpreted as film diffusion.

From the slop of the straight line attained from time versus $\mathrm{B}_{t}$ graph, the $\mathrm{B}$ value (time constant) were calculated. The values of effective diffusion coefficient $\left(D_{i}\right)$ were calculated at different temperatures using the fol- 
TABLE VII. Effective diffusion coefficient $\left(\mathrm{D}_{i}\right)$ pre exponential constants $\left(\mathrm{D}_{o}\right)$, activation energy $\left(\mathrm{E}_{a}\right)$ and entropy of activation $\Delta \mathrm{S}^{\#}$ for diffusion of Basic Green 4 (BG 4) in TWAC.

\begin{tabular}{|c|c|c|c|c|c|c|}
\hline \multirow{2}{*}{ Adsorbent } & \multicolumn{3}{|c|}{$\mathrm{D}_{i}\left(\mathrm{~m}^{2} / \mathrm{s}\right)$} & \multirow{2}{*}{$\begin{array}{c}\mathrm{D}_{0} \\
\mathrm{~m}^{2} / \mathrm{s}\end{array}$} & \multirow{2}{*}{$\begin{array}{c}\mathrm{E}_{a} \\
\mathrm{~kJ} / \mathrm{mol}\end{array}$} & \multirow{2}{*}{$\begin{array}{c}\Delta \mathrm{S}^{\#} \\
\mathrm{~J} \mathrm{~K}^{-1} \mathrm{~mol}^{-1}\end{array}$} \\
\hline & $30^{\circ} \mathrm{C}$ & $45^{\circ} \mathrm{C}$ & $60^{\circ} \mathrm{C}$ & & & \\
\hline TWAC & $3.67 \times 10^{-11}$ & $4.02 \times 10^{-11}$ & $4.49 \times 10^{-11}$ & $7.78 \times 10^{-5}$ & -5662 & -154.99 \\
\hline MWNTs & $3.51 \times 10^{-11}$ & $3.56 \times 10^{-11}$ & $4.27 \times 10^{-11}$ & $7.22 \times 10^{-5}$ & -5399 & -156.42 \\
\hline
\end{tabular}
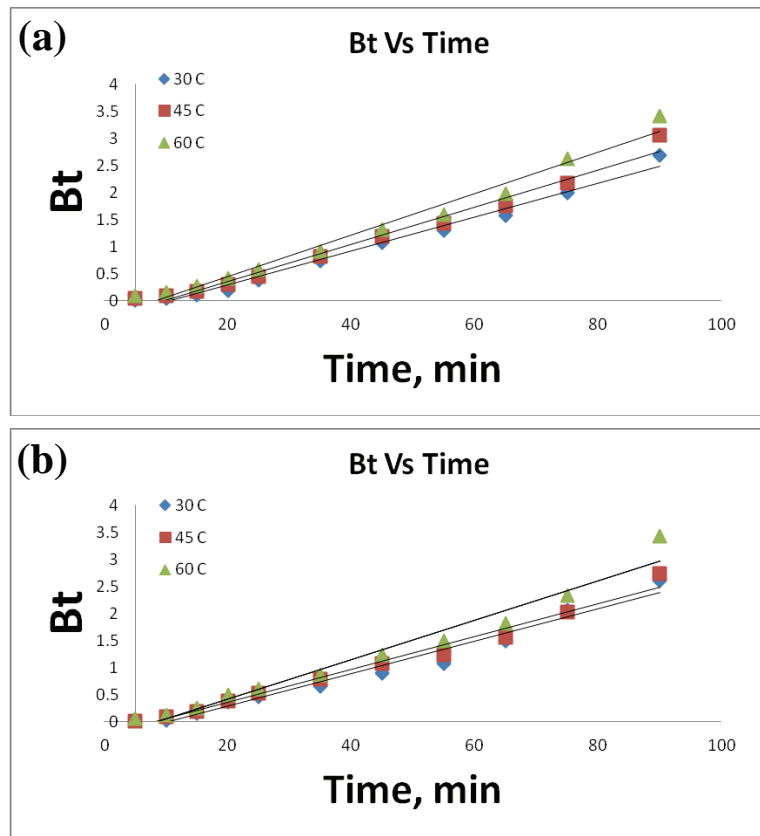

FIG. 7. Time vs $B_{t}$ plots different temperature of Basic Green 4 (BG 4) (a) TWAC adsorption and (b) MWNTs adsorption.

lowing equation:

$$
B=\frac{\pi^{2} D_{i}}{r^{2}}
$$

Here $r$ is the radius of the absorbent particle. The $D_{i}$ values are given in the Table VII. The plot of $1 / T$ versus $\log D_{i}$ was obtained linear (not given) with negative slope indicating thereby the increase in the mobility of species. This is due to the fact that with the rise in temperature the mobility of species increases, which consequently decreases the retarding force acting on the diffusing species.
The Values of energy of activation $E_{a}$, entropy of activation $\Delta S^{\#}$ and pre-exponential constant $D_{o}$ were calculated using following equations:

$$
\begin{aligned}
& D_{i}=D_{o} \exp \left[-E_{a} / R T\right] \\
& D_{o}=\left(2.72 d^{2} k T / h\right) \cdot \exp \left[\Delta S^{\#} / R\right],
\end{aligned}
$$

where $d$ is the average distance between the subsequent exchange sites and is taken as $5 \AA$. $R, h$ and $k$ are the Gas, Plank, and Boltzmann constants, respectively. The values of $E_{a}, D_{i}, D_{o}, \Delta S^{\#}$ and other data are given in Table VI. The negative value of $\Delta S^{\#}$ reflects that no appreciable change occurs in the internal structure of chosen adsorbents during the time of adsorption process.

\section{CONCLUSIONS}

Removal of Basic Green 4 (BG 4) from aqueous solution was possible using several abundantly available low cost adsorbents. The adsorption of Basic Green 4 (BG 4) was found to be dependent on $\mathrm{pH}$, temperature and concentration for both TWAC and MWNTs type adsorbents. Thermodynamic parameters obtained for both adsorbents account for feasibility of the process at each concentration. In addition, the kinetic studies probably proved that the removal takes through a film diffusion process at all the concentrations and temperatures for both TWAC and MWNTs. The percentage saturation was found to be almost $92 \%$ and $93 \%$ for TWAC and MWNTs respectively. The kinetics of Basic Green 4 (BG 4) adsorption on the both adsorbents was found to correlate a pseudo secondorder rate equation.

\section{ACKNOWLEDGMENTS}

The authors acknowledge the M.A.M. College of Engineering, Tiruchirappalli and The Institute for Environmental Nanotechnology, Erode and BIT Campus, Anna University, Tiruchirappalli for encouragement and constant support for this project.
[1] S. Babel and T. A. Kurniawan, J. Hazard. Mater. 97, 219 (2003).

[2] A. Macías-García, C. Valenzuela-Calahorro, V. GomézSerrano, and A. Espínosa-Mansilla, Carbon 31, 1249 (1993).

[3] L. D. Benefield, J. F. Judkins, and B. L. Weand, Process chemistry for Water and Wastewater Treatment (Prentice-Hall, Englewood Cliffs, 1982), p. 405.
[4] T. K. Manimekalai, N. Sivakumar, and S. Periyasamy, Digest Journal of Nanomaterials and Biostructures 10, 985 (2015).

[5] A. M. Youseff, M. R. Mostafa, and E. M. Dorgham, Afinidad 47, 41(1990).

[6] D. Roy, P. N. Greenlaw, and B. S. Shane, J. Environ. Sci. Health A 28, 37 (1993). 
[7] C. Namasivayam and K. Periasamy, Water Res. 27, 1663 (1993).

[8] S. J. Allen, G. McKay, and K. Y. H. Khader, Environ. Pollut. 56, 39 (1989).

[9] B. Chen, C. W. Hui, and G. McKay, Water Res. 35, 3345 (2001).

[10] S. Karthikeyan, P. Sivakumar, and P. N. Palanisamy, E-J. Chem. 5, 409 (2008).

[11] S. Karthikeyan, G. Bhuvaneswari, S. Malathi, P. Maheswari, and B. Sivakumar, J. Ind. Council Chem. 24, 63 (2007).

[12] S. Karthikeyan and P. Sivakumar, J. Environ. Nanotechnol. 1, 5 (2012).

[13] K. Sakthivel, I. Arockiaraj, C. Kannan, and S. Karthikeyan, J. Environ. Nanotechnol. 2, 66 (2013).

[14] K. T. Karthikeyan and K. Jothivenkatachalam, J. Environ. Nanotechnol. 3, 69 (2014).

[15] T. Maiyalagan and S. Karthikeyan, Indian J. Chem. Technol. 20, 7 (2013).

[16] B. Sivakumar, S. Karthikeyan, and C. Kannan, Digest Journal of Nanomaterials and Biostructures 5, 657 (2010).

[17] P. Shanthi, G. Tamilarasan, K. Anitha, and S. Karthikeyan, Rasayan J. Chem. 7, 229 (2014).

[18] S. Karthikeyan and P. Mahalingam, Int. J. Green Nanotechnol.: Physics and Chemistry 2, 39 (2010).

[19] S. Brunauer, P. H. Emmett, and E. Teller, J. Am. Chem. Soc. 60, 309 (1938).

[20] S. Lagergren, Kungliga Svenska Vetenskapsakademiens Handlingar 24, 1 (1898).

[21] Y. S. Ho, J. C. Y. Ng, and G. McKay, Separation \& Purification Reviews 29, 189 (2000).

[22] S. H. Chien and W. R. Clayton, Soil. Sci. Soc. Am. J. 44, 265 (1980).

[23] I. Langmuir, J. Am. Chem. Soc. 40, 1361 (1918).

[24] H. Freundlich, Zeitschrift für Physikalische Chemie 57, 384 (1906).
[25] A. Shukla, Y. H. Zhang, P. Dubey, J. L. Margrave, and S. S. Shukla, J. Hazard. Mater. 95, 137 (2002).

[26] S. D. Khattri and M. K. Singh, Indian J. Chem. Technol. 6, 112 (1999).

[27] S. Inbaraj and N. Sulochana, Indian J. Chem. Technol. 9, 201 (2002).

[28] P. Mahalingam, T. Maiyalagan, E. ManiKandan, P. S. Syed Shabudeen, and S. Karthikeyan, J. Environ. Nanotechnol. 2, 43 (2013).

[29] A. Stafiej and K. Pyrzynska, Sep. Purif. Technol. 58, 49 (2007).

[30] Q. Li, J. Zhang, Y. Hao, M. He, and Z. Liu, Carbon 42, 287 (2004).

[31] V. V. Simonyan, J. K. Johnson, A. Kuznetsova, and J. T. Yates Jr., J. Chem. Phys. 114, 4180 (2001).

[32] F. J. A. L. Cruz, I. A. A. C. Esteves, and J. P. B. Mota, Colloids and Surfaces A: Physicochem. Eng. Aspects 357, 43 (2010).

[33] Y. H. Shih and M. S. Li, J. Hazard. Mater. 154, 21(2008).

[34] Y. J. Xu and J. Q. Li, Chem. Phys. Lett. 400, 406 (2004).

[35] V. K. Gupta, A. Mittal, and V. Gajbe, J. Colloid Interface Sci. 284, 89 (2005).

[36] V. K. Gupta, I. Ali, Suhas, and D. Mohan, J. Colloid Interface Sci. 265, 257 (2003).

[37] W. J. Weber and J. C. Morris, J. Sanitary Eng. Div. 89, 31 (1963).

[38] L. D. Michelson, P. G. Gideon, A. G. Page, and L. H. Kutal, US Department Industry, Office of Water Research and Technology, Bulletin No. 74 (1975).

[39] A. K. Bhattacharya and C. Venkobachar, J. Environ. Eng. 110, 110 (1984).

[40] G. E. Boyd, A. W. Adamson, and L. S. Myers Jr., J. Am. Chem. Soc. 69, 2836 (1947).

[41] D. Reichenberg, J. Am. Chem. Soc. 75, 589 (1953). 